\title{
Influence of bilirubin on surface tension properties of lung surfactant
}

\author{
Maurizio Amato, Samuel Schürch, Rolf Grunder, Hans Bachofen, Peter H Burri
}

\begin{abstract}
Aim-To investigate the influence of bilirubin on the surface tension activity of a porcine derived (Curosurf) and synthetic (Exosurf) surfactant.

Methods-The captive bubble surfactometer at phospholipid doses of $0.5 \mathrm{mg} / \mathrm{ml}$ (low dose) and $1 \mathrm{mg} / \mathrm{ml}$ (high dose) in solutions of increasing bilirubin concentrations $(0.25,0.5$, and $1.0 \mathrm{mg} / \mathrm{ml})$ was used.
\end{abstract}

Results-Curosurf (without bilirubin) showed a higher surface tension activity than Exosurf, as shown by area compression of 30 (SD 0.6 )\% compared with $76(1.4) \%$ at low surfactant dose and 25 (0.9)\% compared with $85(0.5) \%$ at high dose $(\mathbf{P}<0.01)$. Bilirubin showed negligible surface activity at the concentrations studied. At low phospholipid dose (0.5 $\mathrm{mg} / \mathrm{ml}$ Curosurf), bilirubin increased film area compression of lipid extract surfactant from $30(0.6) \%$ to $55(1.6) \%, 59$ $(0.1) \%$, and $68(0.5) \%$ at the three studied bilirubin concentrations, respectively (P<0.01). At high phospholipid dose (1 $\mathrm{mg} / \mathrm{ml}$ Curosurf), bilirubin had the same adverse, although less pronounced, effect on film area compression of porcine lipid extract surfactant $(25(0.9) \%$ vs $26(0.9) \%$, $39(1.3) \%$, and $44(1.1) \%$, respectively) $(\mathbf{P}<0.01)$. Using synthetic surfactant (Exosurf), with a much lower original surface activity, bilirubin did not further inhibit its surface tension properties at any of the phospholipid doses studied.

Conclusion-These results indicate that in vitro bilirubin impairs the surface tension activity of porcine lipid extract surfactant, but does not affect synthetic surfactant activity.

(Arch Dis Child 1996;75:F191-F196)

Keywords: bilirubin, surfactant, surface tension, respiratory distress syndrome.

The intratracheal administration of exogenous surfactant in infants with respiratory distress syndrome (RDS) reduces the severity of respiratory distress and neonatal mortality. ${ }^{12} \mathrm{Al}-$ though a variety of lipid extract and synthetic surfactants are therapeutically effective, 5 to $30 \%$ of infants with RDS do not respond favourably to surfactant treatment. ${ }^{34}$

Most interest in hyperbilirubinaemia in neonates has focused on the toxic effects of bilirubin on the central nervous system. ${ }^{5}$ By contrast, little work has been directed at other organ systems where high serum concentration of bilirubin might have a pathogenetic role. In very low birthweight infants with RDS and hyperbilirubinaemia, bilirubin can enter the alveolar space in fluid leaking from capillaries, where its presence at necropsy has been called "yellow hyaline membrane disease." However, there is little information on whether this entity reflects disordered surface activity of surfactant in vivo and in vitro. Preliminary studies have focused on the effect of acidosis on bilirubin-lipid extract surfactant interaction. ${ }^{\text {? }}$

However, it is well known that the inhibiting effects of plasma proteins on surfactant in vitro are most pronounced at low surfactant concentrations and that this effect can be reversed by increasing surfactant concentrations. ${ }^{89}$ Other plasma components, such as bilirubin, acting by different mechanisms, may exhibit different patterns of concentration dependent surfactant inhibition. ${ }^{10}$

The paucity of data on this topic prompted us to perform a series of experiments with the captive bubble surfactometer (CBS) ${ }^{11}$ to characterise the effects of different bilirubin concentrations on the surface tension lowering properties of two commercially available surfactant preparations: porcine lipid extract (Curosurf) and synthetic surfactant (Exosurf). In accordance with previous reports, we focused our study on the compression of film area required to achieve minimum surface tension because this is a much more sensitive criteria of possible inhibitory effect of bilirubin on surfactant surface activity than the minimum surface tension. ${ }^{12}$ The biophysical results of this study will provide new insights into the in vitro effects of bilirubin on pulmonary surfactant activity. They may also have therapeutic implications for the clinical management of RDS in preterm babies with hyperbilirubinaemia.

\section{Methods}

Two surfactant preparations in current clinical use were investigated. Curosurf (Chiesi Company, Parma, Italy) is a lipid extract surfactant isolated from minced pig lungs using a sequence of washing, centrifugation, chloroform-methanol extraction and liquid gel chromatography. It contains about $99 \%$ polar lipids, mainly phospholipids (30-35\% dipalmitoylphosphatidylcholine or DPPC) and $1 \%$ hydrophobic proteins (SP-B and SP-C) in an approximate molar ratio of $1: 2 .^{13}$ Curosurf was supplied as a suspension in unbuffered physiological saline with a phospholipid concentration of $80 \mathrm{mg} / \mathrm{ml}$.

Exosurf (Burroughs-Wellcome Reinach, Basel, Switzerland) is a synthetic surfactant consisting of DPPC, hexadecanol, and tyloxapol in a proportion of $13.5 / 1.5 / 1 \mathrm{mg} / \mathrm{ml}$. 
Exosurf is a lyophilised powder that was reconstituted as a suspension according to the manufacturer's instructions.

Both surfactant preparations were stored at $-20^{\circ} \mathrm{C}$ until use. After the phial was opened to remove the amount of surfactant needed for a series of experiments during a period of about 4 hours the phial was immediately capped and stored at $2-3^{\circ} \mathrm{C}$ for a maximum of three days. For the experiments, phospholipid concentration in the samples was adjusted to $0.5 \mathrm{mg} / \mathrm{ml}$ and $1 \mathrm{mg} / \mathrm{ml}$ by adding $0.9 \% \mathrm{NaCl}$. Greater lipid concentrations could not be studied, in as much as discerning the edges of the bubbles in the presence of bilirubin was too difficult, the suspensions being too murky. Independent experiments were performed using both surfactant preparations alone, which served as control group.

Crystalline bilirubin (Sigma Chemical Co, St Louis, MO, USA) was dissolved in $0.05 \mathrm{M}$ $\mathrm{NaOH}$ and buffer at $\mathrm{pH}$ 7.4. For all experiments with bilirubin the final measured $\mathrm{pH}$ in the solution was 7.35. Bilirubin solutions were prepared, protected from light, and added to the cited surfactant solutions, in a ratio of $1: 1$ to $1: 4$, such that the final bilirubin concentrations were $0.25 \mathrm{mg} / \mathrm{ml}, 0.5 \mathrm{mg} / \mathrm{ml}$, and 1.0 $\mathrm{mg} / \mathrm{ml}$. The ratio was estimated considering surfactant pool size and bilirubin concentration in the monolayer of immature lungs after adsorption. ${ }^{14}{ }^{15}$ Control experiments were also conducted with bilirubin solutions, without adding surfactant.

The captive bubble method is an in vitro technique developed for the determination of the surface tension and area of a bubble with a surfactant film at the air-liquid interface. Recognition of leakage problems with more conventional methods (Wilhelmy-Langmuir Balance and Pulsating Bubble Surfactometer) ${ }^{1617}$ prompted Schürch et $a l^{11}$ to develop the captive bubble apparatus used in this study. In this system the captive bubble is floated against a $1 \%$ agarose gel and the glass chamber is sealed and pressurised, thereby decreasing air volume. Furthermore, this system has the advantage of being leak free because there are no plastic walls or tubes that interrupt the surface film and offer escape routes for the film material on plasticwater or plastic-air interfaces. Bubble size, and thus the surface tension of any insoluble film at the bubble surface, is altered by changing the pressure within the closed chamber.

Details of the design and construction of the apparatus have been described by Schürch et $a l .{ }^{18}$ The temperature of the chamber is regulated and maintained at $37^{\circ} \mathrm{C}$. The sample chamber is filled with the suspension to be investigated and a bubble of about $6 \mathrm{~mm}$ in diameter is introduced in the chamber. Surfactant films are formed by adsorption from the surfactant suspension. The chamber content is 1 to $2 \mathrm{ml}$ and the bubble in the suspension is compressed or expanded by moving the glass chamber upward or downward keeping the piston in a fixed position. The chamber is mounted on to a movable stage of a microscope stand, and the microscope focusing knob serves to control the movement.
The bubble in the suspension is recorded continuously throughout the experiment on a video recorder (Panasonic NV-FS100 HQ with Monitor BT-M1400 PSN and Sony XC-75CE Camera) and the images are printed by video printer (Sony video graphic UP860CE). The bubble surface tension and area are calculated using the recently developed polynomials in bubble height (h) and diameter (d) for bubble with a $180^{\circ}$ contact angle - that is, for nonadhering bubbles. Coefficients for the surface tension polynomials were obtained analytically from the published polynomials in $\mathrm{h} / \mathrm{d}$ by $\mathrm{Mal}-$ colm and Elliott. ${ }^{19}$ Coefficients for the area polynomial were obtained from $h$ and $d$, and from measured areas of revolution of calibrating bubbles. Using the method of Schoel et al ${ }^{13}$ for calculating bubble surface tension and area, only $\mathrm{h}$ and $\mathrm{d}$ are required as input. This method shows good agreement (within 1\%) with the method described by Neumann and associates, ${ }^{20}$ that has been used as a standard for comparison of surface tension, area, and volume determination of asymmetric bubbles and drops, having contact angles $<180^{\circ}$.

For adsorption measurements (ST-max), a 20-gauge needle (flat tip) was introduced through the bottom inlet of the chamber. The needle tip was moved up to within $1 \mathrm{~cm}$ of the agarose ceiling, and the needle was held in this position by friction. Stirring was started at this point and continued during the adsorption period. A 6 to $7 \mathrm{~mm}$ in diameter bubble was then formed by turning the focusing knob of the microscope stand by about $90^{\circ}$ as quickly as possible. The transition time for the bubble formation from the first appearance of air at needle tip to the resting position at the agarose ceiling, was $<0.17$ seconds, as measured by counting single frames on the television monitor. After this interval, the bubble has assumed a Laplacian shape (time 0 for adsorption). The bubble was then continuously recorded during the adsorption period and the following quasistatic examinations were performed. For the present study, we used printed video images and determined height and diameter to \pm 0.5 $\mathrm{mm}$. The calculated relative error ranged from about $8 \%$ for surface tensions $<3.0 \mathrm{mN} / \mathrm{m}$ to about $5 \%$ for surface tensions $>30 \mathrm{mN} / \mathrm{m}$.

After 5 minutes of adsorption to a stable level, the film was compressed stepwise with a pause at each step until the bubble shape no longer changed noticeably within $20-30 \mathrm{sec}-$ onds, which corresponds to a change in surface tension of $<0.5 \mathrm{mN} / \mathrm{m}$. About 10 steps were taken for each compression. Quasi-static cycling involves a series of small alterations in bubble area where the surface film is allowed partially to relax during the compression process. Film collapse at minimum surface tension was avoided, in as much as the bubble area was re-expanded just after minimum surface tension was reached.

We calculated maximum surface tension (STmax) and maximum surface area (area $\max$ ) after the 5 minute adsorption period, and minimum surface tension (STmin) and the corresponding minimum surface area (area min) after bubble compression. 
Table 1 Mean (SD) adsorption for lipid extract surfactant (Curosurf) and synthetic surfactant (Exosurf) at increasing bilirubin concentrations $(n=12)$

\begin{tabular}{llll}
\hline & \multicolumn{3}{l}{ Maximum surface tension $(\mathrm{mN} / \mathrm{m})$} \\
\cline { 2 - 4 } Bilirubin & Curosurf & Exosurf & P value \\
\cline { 2 - 4 } & $0.5 \mathrm{mg} / \mathrm{ml}$ & $0.5 \mathrm{mg} / \mathrm{ml}$ & \\
\hline Control & $24.6(2.1)$ & $36.4(1.9)$ & $<0.01$ \\
$0.25 \mathrm{mg} / \mathrm{ml}$ & $29.0(5.6)$ & $35.3(5.2)$ & $<0.05$ \\
$0.5 \mathrm{mg} / \mathrm{ml}$ & $33.9(9.6)$ & $36.2(4.3)$ & $>0.5$ \\
$1.0 \mathrm{mg} / \mathrm{ml}$ & $29.9(4.4)$ & $35.9(6.2)$ & $<0.05$ \\
& $1.0 \mathrm{mg} / \mathrm{ml}$ & $1.0 \mathrm{mg} / \mathrm{ml}$ & \\
Control & $24.8(2.2)$ & $35.9(1.4)$ & $<0.01$ \\
$0.25 \mathrm{mg} / \mathrm{ml}$ & $24.9(2.4)$ & $34.8(3.1)$ & $<0.01$ \\
$0.5 \mathrm{mg} / \mathrm{ml}$ & $27.6(6.4)$ & $35.7(4.1)$ & $<0.05$ \\
$1.0 \mathrm{mg} / \mathrm{ml}$ & $31.4(6.1)$ & $36.1(3.5)$ & $<0.05$ \\
\hline
\end{tabular}

Minimum surface tension is obtained when, during the compression phase, the bubble shape ceases to flatten, accompanied by a decreasing bubble diameter. When measuring the surface tension lowering properties of surfactant films, one of the most sensitive parameters to consider is the area compression required to achieve minimum surface tensions. Area compression was calculated in per cent of the initial area values using the formula:

[(Area max-Area min)/ Area max] x 100.

STATISTICAL ANALYSIS

Data of maximum, minimum surface tension, and relative area compression are expressed as mean (SD) and analysed using statistical analysis program software (Statview SE and Graphics, Abacus Concepts, Inc., Berkeley, California). Significance between the different experiments was calculated using the ANOVA test. Values of $P<0.05$ were considered significant.

\section{Results}

The adsorption (ST-max) of surfactant and bilirubin into the air-liquid interface of a bubble was calculated by examining single video frames. The time at which the bubble came to rest at the agarose ceiling was taken as time $O$ for adsorption. For lipid extract surfactant samples, adsorption was always rapid, reaching near equilibrium values between 24 and about $34 \mathrm{mN} / \mathrm{m}$ within 2 seconds. Table 1 summarises the surface tension values after 5 minutes of adsorption (ST max) of surfactant controls and surfactants in combination with bilirubin.

Adsorption for synthetic surfactant was slower than that for lipid extract surfactant, reaching a plateau value between 34 and 37 $\mathrm{mN} / \mathrm{m}$, and was not influenced by bilirubin at any chosen concentration and phospholipid dose. Adsorption (5 minutes) of Curosurf in the presence of bilirubin was mainly affected at low phospholipid dose of $0.5 \mathrm{mg} / \mathrm{ml}$, giving higher surface tensions above $33 \mathrm{mN} / \mathrm{m}$ compared with about $24 \mathrm{mN} / \mathrm{m}$ for Curosurf controls. At higher Curosurf doses $(1.0 \mathrm{mg}$ ) $\mathrm{ml}$ ), the effect on adsorption in the presence of bilirubin was less pronounced, giving significant values above $31 \mathrm{mN} / \mathrm{m}$ only at the higher bilirubin concentration of $1.0 \mathrm{mg} / \mathrm{ml}$, compared with about $25 \mathrm{mN} / \mathrm{m}$ for Curosurf controls. Significant differences in maximum surface tension (after 5 minutes of adsorption)
Table 2 Mean (SD) minimum surface tension values for lipid extract surfactant (Curosurf) and synthetic surfactant (Exosurf) at increasing bilirubin concentrations ( $n=12)$

\begin{tabular}{llll}
\hline \multirow{4}{*}{ Bilirubin } & \multicolumn{3}{l}{ Minimum surface tension $(\mathrm{mN} / \mathrm{m})$} \\
\cline { 2 - 4 } & Curosurf & Exosurf & P value \\
\cline { 2 - 4 } & $0.5 \mathrm{mg} / \mathrm{ml}$ & $0.5 \mathrm{mg} / \mathrm{ml}$ & \\
\hline Control & $3.6(1.2)$ & $3.1(2.0)$ & $>0.5$ \\
$0.25 \mathrm{mg} / \mathrm{ml}$ & $3.7(1.1)$ & $3.2(1.2)$ & $>0.5$ \\
$0.5 \mathrm{mg} / \mathrm{ml}$ & $4.0(1.2)$ & $3.9(1.5)$ & $>0.5$ \\
$1.0 \mathrm{mg} / \mathrm{ml}$ & $9.9(2.0)$ & $3.2(0.5)$ & $<0.01$ \\
& $1.0 \mathrm{mg} / \mathrm{ml}$ & $1.0 \mathrm{mg} / \mathrm{ml}$ & \\
Control & $3.6(1.2)$ & $3.5(1.0)$ & $>0.5$ \\
$0.25 \mathrm{mg} / \mathrm{ml}$ & $3.1(1.0)$ & $4.0(1.0)$ & $>0.5$ \\
$0.5 \mathrm{mg} / \mathrm{ml}$ & $3.4(0.5)$ & $3.5(1.5)$ & $>0.5$ \\
$1.0 \mathrm{mg} / \mathrm{ml}$ & $3.2(0.5)$ & $5.2(2.1)$ & $>0.5$ \\
\hline
\end{tabular}

were noted between both surfactant preparations at 0.5 and $1.0 \mathrm{mg} / \mathrm{ml}$ phospholipid doses. At all bilirubin concentrations, especially at high surfactant dosage $(1 \mathrm{mg} / \mathrm{ml})$, adsorption of lipid extract surfactant was faster than adsorption of synthetic surfactant (table 1).

Control experiments using only bilirubin (at $\mathrm{pH} 7.35$ ) showed negligible surface activity of this substance at any chosen concentration $(0.25,0.5$, and $1.0 \mathrm{mg} / \mathrm{ml})$. Mean (SD) maximum surface tension values for bilirubin were 43.9 (10.9) $\mathrm{mN} / \mathrm{m}$ and mean minimum surface tension values $10.1 \quad(3.30 \mathrm{mN} / \mathrm{m}$ (significantly different values vs control experiments with both surfactant preparations).

After equilibrium surface tension was reached, static cycles were performed by increasing the pressure in the sample chamber stepwise, as already described.

Minimum surface tension (ST-min) was obtained when the bubble either ceased to decrease in height or when the bubble suddenly clicked during compression in small steps. ${ }^{21}{ }^{22}$ Minimum surface tensions were substantially higher than the control values, but only for Curosurf at low phospholipid dose $(0.5 \mathrm{mg} / \mathrm{ml})$ in combination with bilirubin at high concentration $(1 \mathrm{mg} / \mathrm{ml})$. The minimum surface tension obtained after the adsorption period for low dose Curosurf in the presence of $1 \mathrm{mg} / \mathrm{ml}$ bilirubin was 9.9 (2.0) $\mathrm{mN} / \mathrm{m}$, showing the greatest inhibition of surface activity compared with control experiments and experiments using synthetic surfactant.

Minimum surface tensions returned to the normal range $(3.2(0.5) \mathrm{mN} / \mathrm{m})$ at high phospholipid concentration showing that the influence of bilirubin on surface tension properties of lipid extract surfactant is dose dependent. In contrast to lipid extract surfactant, minimum surface tension of synthetic surfactant was not affected by bilirubin at any chosen concentration (table 2).

Figures 1 and 2 show the effect of increasing bilirubin concentrations on area compression (AC) required to achieve the above mentioned minimum surface tension for both surfactant preparations at different phospholipid concentration.

Synthetic surfactant films have to be compressed far more to achieve minimum surface tension than lipid extract surfactant films (area compression, control experiments: $30(0.6) \%$ for Curosurf vs 76 (1.4)\% for Exosurf in the 


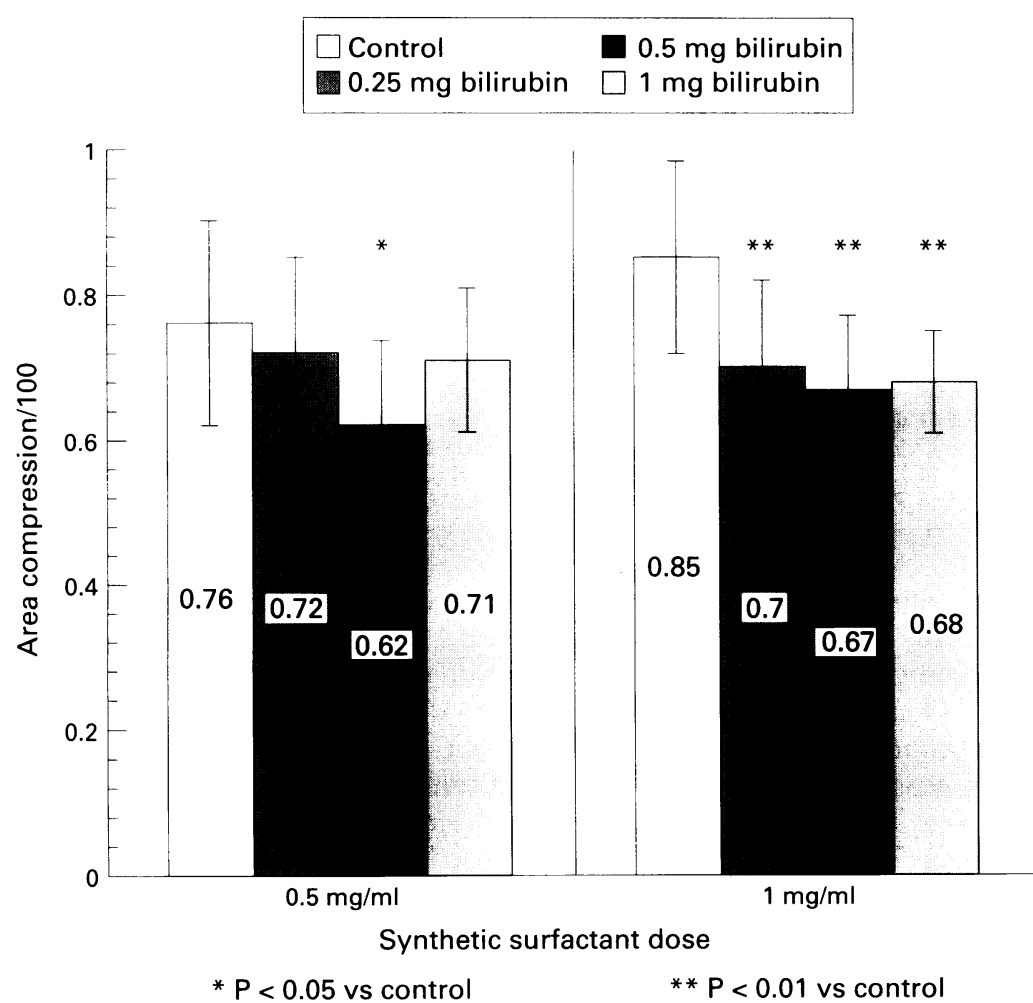

Figure 1 Film area compression $(A C)$ vs surfactant concentration obtained from experiments on synthetic surfactant (Exosurf). The addition of bilirubin to synthetic surfactant shows that the area compression to achieve minimum surface tension decreases at low $(0.5 \mathrm{mg} / \mathrm{ml})$ and high $(1 \mathrm{mg} / \mathrm{ml})$ phospholipid dose. These data indicate no deterioration in the original surface tension lowering properties of synthetic surfactant in the presence of bilirubin. compression is required to achieve minimum surface tensions in the presence of bilirubin (55 (1.6)\%, $59(0.10) \%$, and $68(0.5) \%$ at $0.25,0.5$, and $1.0 \mathrm{mg} / \mathrm{ml}$ bilirubin concentrations, respectively). At high Curosurf dose (1 $\mathrm{mg} / \mathrm{ml}$ ) this effect was still present but less pronounced (26 (0.9)\%, 39 (1.3)\%, and 44 $(1.1) \%$ at $0.25,0.5$, and $1.0 \mathrm{mg} / \mathrm{ml}$ bilirubin, respectively) $(\mathrm{P}<0.01$ vs controls for the last two values), indicating a negative correlation between surfactant inhibition by bilirubin and surfactant concentration in the solution (fig 1). In contrast, this detrimental effect of bilirubin on the surface activity of lipid extract surfactant could not be observed using synthetic surfactant. Bilirubin did not inhibit the surface tension properties of Exosurf at low (0.5 $\mathrm{mg} / \mathrm{ml})(72(1.3) \%, 62(1.2) \%$, and $71(1.0) \%$ at the three different bilirubin concentrations, respectively) and high phospholipid dose $(1 \mathrm{mg} / \mathrm{ml})(70 \quad(1.5) \%, 67(1.3) \%$, and 68 $(0.7) \%$, respectively), as shown by lower area compression values observed in the presence of bilirubin (fig 2 ).

\section{Discussion}

In the past three decades, investigators have attempted to develop exogenous surfactants for use in replacement treatment. Some of these preparations, including complex protein free mixtures involving phospholipid components found in natural surfactant, have shown promising biophysical characteristics and are in current clinical use for the treatment of neonatal RDS. ${ }^{2324}$

However, inhibition of pulmonary surfactant may be a major cause of the abnormally increased surface tensions found in several respiratory diseases, including neonatal respiratory distress syndrome. ${ }^{25}$ Several in vitro studies have shown that albumin, haemoglobin, fibrinogen, fibrin monomer and free fatty acids inhibit surfactant. ${ }^{132627}$ However, the role and importance of other endogenous molecules which could, in theory, interfere with surfactant biophysical activity are less certain. Data on experimental meconium aspiration syndrome suggest that free fatty acids and bilirubin reduce lung compliance, probably as a result of surfactant inhibition. ${ }^{28}$

Bilirubin, in high concentration, is toxic to the brain of premature babies. Impaired psychomotor performance and hyperbilirubinaemia (bilirubin concentrations $>10$ to 14 $\mathrm{mg} / \mathrm{dl}$ ) has been reported in low birthweight infants. ${ }^{8}$ Serum bilirubin concentrations range from 0.3 to $1.0 \mathrm{mg} / \mathrm{dl}$ in adults and from 1.0 to $25 \mathrm{mg} / \mathrm{dl}$ in neonates. Bilirubin is found in body fluids (cerebrospinal fluid, joint effusions, cysts, lung fluid, etc.) in proportion to the albumin content of the fluids, the perfusion rate, and the amount of oedema in the tissues. ${ }^{29}$

In previous studies on bilirubin toxicity, numerous effects of bilirubin have been observed, most of them on membrane related processes. ${ }^{30}$ The pigment alters several mitochondrial functions, to inhibit membrane bound enzymes such as ATPase or protein kinase $C$, and to affect ion membrane permeability and synaptosomal membrane potential low dose group and $25(0.9) \%$ vs $85(0.5) \%$ in the high dose group. Furthermore, using lipid extract surfactant $(0.5 \mathrm{mg} / \mathrm{ml})$, increasing area 
in a dose dependent manner. ${ }^{31}$ Furthermore, bilirubin has been reported to interact with mitochondrial membranes, erythrocyte membranes, phospholipid bilayers and gangliosides. ${ }^{32}$ However, there is a lack of information about the possible biochemical interaction of bilirubin with surfactant components in some pathophysiological circumstances.

Until now, the most popular methods to measure the in vitro behaviour of pulmonary surfactants were the Wilhelmy-Langmuir method, introduced by Clements ${ }^{16}$ and the pulsating bubble surfactometer described by Enhorning. ${ }^{17}$ In both methods leakage in the system is a complication causing potential artefacts. In the captive bubble system introduced by Schürch et al, ${ }^{11}$ surfactant films may be compressed to minimum surface tension without leakage, and the corresponding film area compression required to achieve minimum surface tension can then be precisely determined.

In recent in vitro studies, using the captive bubble method, ${ }^{18}$ it has been shown that, whereas the effects of serum proteins on minimum surface tension were similar to those reported by others, the per cent reduction in film area required to achieve minimum surface tension is a much more sensitive measure of the effect of surfactant inhibiting substances on surface activity than is the measure of minimum surface tension.

In our experiments surface tension was reduced by compressing the film area in a quasi-static manner until minimum surface tension was achieved. At low phospholipid concentration $(0.5 \mathrm{mg} / \mathrm{ml})$, bilirubin had the most impressive effect on natural surfactant stability, showing a dose-effect relation between surfactant and bilirubin concentrations. Surfactant films initially compressed by only about $30 \%$ had to be compressed by $75 \%$ to reach near zero tensions after adding bilirubin. This effect was shown, but in a less pronounced manner, at higher phospholipid dose $(1 \mathrm{mg} / \mathrm{ml})$ where the film area reduction necessary to reach minimum surface tension changed from $25 \%$ to about $50 \%$.

In control experiments synthetic surfactant films had to be compressed by 80 to $85 \%$ to reach near zero tensions after repeated cycling, showing a smaller surface tension lowering capacity of synthetic surfactant than lipid extract surfactant.

The question is why bilirubin impairs the activity of porcine lipid extract surfactant (Curosurf) and not that of synthetic surfactant (Exosurf). Figures 1 and 2 show that standard Exosurf has lower surface activity than standard Curosurf and its performance is not influenced by bilirubin. Differences in the chemical composition of the two surfactant preparations could be responsible for the different results. Exosurf is a mixture of DPPC, a high molecular alcohol and a non-ionic detergent.

In a recent study Findlay et $a l^{3}$ showed that the non-DPPC components of synthetic surfactant may have a cytotoxic effect on alveolar type II cells. Non-ionic detergents, like tyloxapol, are commonly used in the laboratory to induce haemolysis. It is possible that alcohol and/or the detergent of synthetic surfactant "neutralise" the adverse effect of bilirubin on the DPPC layer at the air-liquid interface, which is the essential component of surfactant surface activity. However, more attractive is the hypothesis that there is a biochemical interaction between bilirubin and the specific surfactant proteins SP-B and/or SP-C which results in an impaired surface activity of lipid extract surfactant. Considering the different components of pulmonary surfactant, this last hypothesis could explain the different conclusions of our study from those of Notter et al. ${ }^{10}$ Further studies are needed to determine whether surfactant associated proteins (SP-B and/or SP-C) are coupled or inactivated by bilirubin during adsorption, spreading, or squeeze-out.

In vitro, the detrimental effect of bilirubin on Curosurf can be overcome by an increase in surfactant concentration. This observation could suggest that the same dose-effect is operative in vivo. However, such an extrapolation must be verified by well designed animal and clinical studies, in that the chemical environment in peripheral air spaces is much more complex. Additional effects of bilirubin on the lungs under different physical conditions are possible. Nevertheless, our in vitro observations might have practical implications for clinical management of jaundice in babies with RDS treated with exogenous surfactant and in babies with meconium aspiration syndrome. ${ }^{28}$

In conclusion, our in vitro study suggests a more aggressive approach to neonatal hyperbilirubinaemia in the presence of RDS or a more aggressive approach to RDS in babies with hyperbilirubinaemia and treated with lipid extract surfactant is warranted. Further studies are needed to document in vivo, in animal experiments with induced hyperbilirubinaemia, the influence of bilirubin on lung function. Furthermore, the biochemical mechanisms of the detrimental effect of bilirubin on surface activity of lipid extract surfactant need to be elucidated.

We thank Chiesi, Sigma, and Wellcome for providing the material for the study, Ursula Gerber for her valuable help in performing the experiments, and Christian Lehmann for technical assistance.

1 Collaborative European Multicenter Study Group (Robertson B). Surfactant replacement therapy for severe neonatal respiratory distress syndrome: an international randomised clinical trial. Pediatrics 1988; 82:683-91.

2 Cummings JJ, Holm BA, Hudak ML, et al. A controlled clinical comparison of four different surfactant preparations in surfactant-deficient preterm lambs. $A m$ Rev Respir Dis 1992; 145:999-1004.

3 Amirkhanian JD, Bruni R, Waring A, Taeusch HW. Inhibition of mixtures of surfactant lipids and synthetic Inhibition of mixtures of surfactant lipids and synthetic sequences of surfactant proteins
Biophys Acta 1991; 1096:355-60.

4 Collaborative European Multicenter Study Group. Factors influencing the clinical response to surfactant replacement therapy in babies with severe respiratory distress syndrome. Eur $\mathcal{f}$ Pediatr 1991;150:433-9.

5 Cashore WJ. The neurotoxicity of bilirubin. Clin Perinatol 1990; 17:437-47.

6 Valdoes-Dapena MA, Nissim JE, Arey JB, Godleski J, Schaaf HD, Haust MD. Yellow pulmonary hyaline membranes. F Pediatr 1976; 89:128-32.

7 Amato M, Schürch S, Bachofen H, Burri P. Effect of acidosis on bilirubin-lipid extract surfactant interaction Biol Neonate 1995; 68:301-7. 
8 Fuchimukai T, Fujiwara T, Takahashi A, Enhorning G. Artificial pulmonary surfactant inhibited by proteins. $\mathcal{f}$ Appl Physiol 1987; 62:429-37.

9 Holm BA, Enhorning G, Notter RH. A biophysical mechanism by which plasma proteins inhibit lung mechanism by which plasma proteins inhibit

10 Notter RH, Shapiro DL, Taubold R, Chen J. Bilirubin interactions with phospholipid components of lung surfactant. Pediatr Res 1982; 16:130-6.

11 Schürch S, Bachofen H, Goerke J, Possmayer F. A captive bubble method reproduces the in situ behavior of lung surfactant monolayers. $\mathcal{F}$ Appl Physiol 1989; 67:2389-96.

12 Green FH, Schürch S, DeSanctis GT, Wallace JA, Cheng S, Prior M. Effects of hydrogen sulfide exposure on surface properties of lung surfactant. F Appl Physiol 1991; 70:1943-9.

13 Schoel WM, Schürch S, Goerke J. The captive bubble method for the evaluation of pulmonary surfactant: surface tension, area and volume calculations. Biochim surface tension, area and volum
Biophys Acta 1994; 1200:281-90.

14 Jobe A, Ikegami M. Surfactant for the treatment of respiratory distress syndrome. Am Rev Respir Dis 1987 tory distress

15 Sun B, Curstedt T, Robertson B. Long-term cycling of surfactant films in Wilhemy balance. $\mathcal{F} \mathrm{Dev}$ Physiol (in press)

16 Clements JA. Surface tension of lung extracts. Proc Soc Exp Biol Med 1957;95:170-2.

17 Enhorning G. Pulsating bubble technique for evaluatin pulmonary surfactant. $₹$ Appl Physiol 1977; 43:198-203.

18 Schürch S, Schürch D, Curstedt T, Robertson B. Surface activity of lipid extract surfactant in relation to film area compression and collapse. $\mathcal{F}$ Appl Physiol 1994; 77:974-86.

19 Malcolm JD, Elliot CD. Interfacial tension from height and diameter of a single profile drop or captive bubble. Canadiameter of a single profile drop or captive bubble. Can

20 Rotenberg Y, Boruvka L, Neumann AW. Determination of surface tension and contact angle from the shapes of surface tension and contact angle from the shapes of
axisymmetric fluid interfaces. $\mathcal{F}$ Colloid Interface Sci 1983; axisymmetric

21 Bachofen H, Schürch S, Urbinelli M, Weibel ER. Relations among alveolar surface tension, surface area, volume and recoil pressure. $\mathcal{f}$ Appl Physiol 1987; 62:1878-87.
22 Schürch S, Bachoten H, Goerke J, Green F. Surface properies of rat pulmonary surfactant studied with the captive bubble method: adsorption, hysteresis, stability. Biochim Biophys Acta 1992;1103:127-36.

23 Horbar JD, Wright LL, Soll RF, et al. A multicenter randomised trial comparing two surfactants for the treatment of neonatal respiratory distress syndrome. $\mathcal{F}$ Pediatr 1993; 123:757-66.

24 Ikegami M, Agata Y, Elkady T, et al. Comparison of four surfactants: in vitro surface properties and responses of preterm lambs to treatment at birth. Pediatrics 1987; 79:38-46.

25 Kobayashi T, Nitta K, Ganzuka M, et al. Inactivation of exogenous surfactant by pulmonary edema fluid. Pediatr Res $1991 ; 29: 353-6$.

26 Hall SB, Lu RZ, Venkitaraman AR, Hyde RW, Notter RH. Inhibition of pulmonary surfactant by oleic acid: mechanisms and characteristics. $\mathcal{f}$ Appl Physiol 1992; 72:170816.

27 Holm BA, Notter RH, Finkelstein JN. Surface property changes from interactions of albumin with natural lung
surfactant and extracted lung lipids. Chem Phys Lipids 1985; 38:287-98.

28 Sun B, Curstedt T, Robertson B.Surfactant inhibition in experimental meconium aspiration. Acta Paediatr 1993;82:182-9.

29 Amato M, Huppi P, Markus D. Assessment of neonatal jaundice in low birth weight infants comparing transcutaneous, capillary and arterial bilirubin levels. Eur 7 Pediat 1990;150:59-61.

30 Brodersen B. Bilirubin: solubility and interaction with albumin and phospholipid. $\mathcal{F}$ Biol Chem 1979; 254:2364-9.

31 Amato M, Kilguss NV, Gelardi NL, Cashore WJ. Doseeffect relationship of bilirubin on striatal synaptosomes in rats. Biol Neonate 1994; 66:288-93

32 Mustafa MG, King TE. Binding of bilirubin with lipid. $f$ Biol Chem 1970; 245:1084-9.

33 Findlay RD, Taeusch HW, Cu RD, Walther FJ. Lysis of red blood cells and alveolar epithelial toxicity by therapeutic pulmonary surfactants. Pediatr Res 1995; 37:26-30. 